present successful application of angiographic embolization in 2 adolescents.

Materials and Methods A 16 years old boy, involved in a scooter accident, presented with a pelvic trauma: extensive bones fractures associated with a large perineal wound extending to scrotum. At TC scan an arterial active bleeding was visible in pelvis. The second patient was a 17 years old polytraumatized boy, victim of a fall, who presented multiple blunt organ injuries (lungs, liver, spleen, left kidney) and bone fractures; at TC scan contrast extravasation was present in the lower pole of the spleen. Both patients were hemodynamically unstable.

Results First patient underwent, by a left femoral access, a selective angiography of hypogastric artery that permitted identification of the bleeding source: a scrotal branch of internal pudendal artery that undergoes embolization. In second patient angiography was conducted by a right femoral access: multiple pseudoaneurysms of the intraparenchymal splenic arteries had been identified and a superselective embolization was performed. Both patients reached hemodynamic stability after procedure. No complications occurred. Conclusions Angiographic embolization can be a support to non operative management of trauma also in pediatric age to permit organ preservation and to avoid additional trauma of open surgery in critical patients.

\section{REVIEW OF 378 ORCHIDOPEXIES}

doi:10.1136/archdischild-2012-302724.1604

M Shoukry, S Clarke, D Decaluwe, S Shamshad, N Madden, M Haddad, M Choudhry. Paediatric Surgery, Chelsea and Westminster Hospital, Imperial College, London, UK

Background /purpose: To review the outcome of undescended and impalpable testes in terms of atrophic testes at initial operation and complications of atrophy and secondary ascent post orchidopexy.

Method Retrospective review of all orchidopexies carried out between February 2007 and October 2010. Demographic details, age at orchidopexy, operative and postoperative findings were obtained. Findings of testicular atrophy at initial operation, postoperative testicular atrophy and ascent were noted.

Results A total of 378 orchidopexies were carried out in 291 patients in this study period. Only $11 \%$ of children underwent orchidopexy at less than one year and $46 \%$ at less than 2 years of age. Average follow up period was 20 months (range 1-40). Outcome is shown in tables 1 and 2 .

Table SEQ Table * ARABIC 1

\begin{tabular}{lr}
\hline Total testes & $n=378$ \\
Left testes & $123(32 \%)$ \\
Right testes & $105(28 \%)$ \\
Bilateral testes & $75(40 \%)$ \\
Atrophy noted at initial operation & $\mathbf{2 1 ( 5 . 5 \% )}$ \\
Atrophy post-orchidopexy & $\mathbf{9 ( 2 . 3 \% )}$ \\
Ascent post-orchidopexy & $\mathbf{5 ( 1 . 3 \% )}$ \\
Missed at follow-up & $55(14.5 \%)$ \\
\hline
\end{tabular}

Table SEO Table * ARABIC 2

\begin{tabular}{lrr}
\hline Palpable \& Impalpable & \\
\hline Total & $332(88 \%)$ & $46(12 \%)$ \\
Left & $104(31 \%)$ & $19(41 \%)$ \\
Right & $92(27 \%)$ & $13(28 \%)$ \\
Bilateral & $68(42 \%)$ & $7(31 \%)$ \\
Atrophy noted at initial operation & $\mathbf{1 4}(\mathbf{4 . 2} \%)$ & $\mathbf{7 ( 1 5 \% )}$ \\
Atrophy post-surgery & $\mathbf{4 ( 1 . 2 \% )}$ & $\mathbf{5 ( 1 1 \% )}$ \\
Ascent post-surgery & $\mathbf{4 ( 1 . 2 \% )}$ & $\mathbf{1 ( 2 \% )}$ \\
Missed at follow-up & $49(14.7 \%)$ & $6(13 \%)$ \\
\hline
\end{tabular}

Conclusions Overall there is higher incidence of atrophic testes noted at initial operation and atrophy post-orchidopexy in impalpable testes. However incidence of these risks is in comparison with the literature in the palpable testes.

\section{NODULAR FASCIITIS IN THE PEDIATRICS POPULATION: A SINGLE CENTER EXPERIENCE}

doi:10.1136/archdischild-2012-302724.1605

TK Pandian, MM Zeidan, KA Ibrahim, AE Zarroug. Division of Pediatric Surgery, Mayo Clinic, Rochester, MN, USA

Background and Aims We aim to describe our experience with nodular fasciitis in the pediatric population, in an attempt to contribute additional information concerning clinical outcomes and management recommendations.

Methods We performed a twenty-year retrospective chart review of patients $\leq 18$ years diagnosed with nodular fasciitis at a single, large, academic institution.

Results Five patients were treated for nodular fasciitis during the study period. The majority $3(60 \%)$ were male. All presented with rapidly enlarging masses that were excised surgically and $4(80 \%)$ of them had no signs of recurrence (one patient was lost to followup). The median age at presentation was 14 years. Most $3(60 \%)$ lesions were located in the upper extremities and 4 (80\%) had no related symptomatology or disability. All lesions were less than 3 -centimeters in greatest dimension- Table 1 for Tumor Characteristics. Pathologic and immunohistochemical data was lacking in our cohort.

Conclusion The characteristics of nodular fasciitis in children at our institution are slightly different than that which has been reported thus far. Due to variability in clinical presentation and histologic findings, additional studies are necessary to provide more practical, consistent and effective management strategies.

\section{HISTOACRYL INJECTION IN MANAGEMENT OF FOURTH BRANCHIAL FISTULA}

doi:10.1136/archdischild-2012-302724.1606

MA Osman. Pediatric Surgical Unit, Surgery Department, Faculty of Medicine, Assiut University, Assiut, Egypt

Purpose The aim of this study is to evaluate a minimal invasive approach in management of fourth branchial fistula using N Butyl Cyanacrylate (Histoacryl), and to study its feasibility.

Patients and Methods Between 2006 and 2011, a retrospective study of 5 children with fourth branchial fistula were treated at Assiut University hospital. Histoacryl (adhesive material) was injected through the tract under general anesthesia. Their age ranged from 2 years to 5.5 years. Three of them were females.

Results All the children presented with discharging fourth branchial fistula. Three of them had left sided fistula. Fistulogram was carried out to all cases, 2 of them had complete fistula. The duration of the procedure ranged between ten to fifteen minutes. No complications were recorded. The duration of follow up ranged from two months to one year. No recurrence was recorded during the period of follow up.

Conclusion Hisoacryl injection of the fourth branchial fistula is an effective, easy and minimal invasive procedure which can be carried out by junior staff. Surgery is a backup if there is failure or recurrence after injection.

\section{7 EFFECT OF WHITE MARBLE ON THE REPAIR OF BONE} DEFECTS IN RATS: EXPERIMENTAL STUDY

doi:10.1136/archdischild-2012-302724.1607 